\title{
Y-box protein-1/p18 fragment identifies malignancies in patients with chronic liver disease
}

\author{
Frank Tacke ${ }^{1 \dagger}$, Nicolas Kanig ${ }^{1,2 \dagger}$, Abdelaziz En-Nia ${ }^{2}$, Thilo Kaehne ${ }^{3}$, Christiane S Eberhardt ${ }^{2}$, Victoria Shpacovitch ${ }^{2}$, \\ Christian Trautwein ${ }^{1}$ and Peter R Mertens ${ }^{2^{*}}$
}

\begin{abstract}
Background: Immunohistochemical detection of cold shock proteins is predictive for deleterious outcome in various malignant diseases. We recently described active secretion of a family member, denoted Y-box (YB) protein-1. We tested the clinical and diagnostic value of YB-1 protein fragment p18 (YB-1/p18) detection in blood for malignant diseases.

Methods: We used a novel monoclonal anti-YB-1 antibody to detect YB-1/p18 by immunoblotting in plasma samples of healthy volunteers $(n=33)$, patients with non-cancerous, mostly inflammatory diseases $(n=60)$, hepatocellular carcinoma (HCC; $n=25)$ and advanced solid tumors $(n=20)$. YB-1/p18 was then tested in 111 patients with chronic liver diseases, alongside established tumor markers and various diagnostic measures, during evaluation for potential liver transplantation.
\end{abstract}

Results: We developed a novel immunoblot to detect the 18 kD fragment of secreted YB-1 in human plasma (YB-1/ p18) that contains the cold-shock domains (CSD) 1-3 of the full-length protein. YB-1/p18 was detected in 11/25 HCC and 16/20 advanced carcinomas compared to 0/33 healthy volunteers and 10/60 patients with non-cancerous diseases. In 111 patients with chronic liver disease, YB-1/p18 was detected in 20 samples. Its occurrence was not associated with advanced Child stages of liver cirrhosis or liver function. In this cohort, YB-1/p18 was not a good marker for HCC, but proved most powerful in detecting malignancies other than HCC (60\% positive) with a lower rate of false-positive results compared to established tumor markers. Alpha-fetoprotein (AFP) was most sensitive in detecting HCC, but simultaneous assessment of AFP, CA19-9 and YB-1/p18 improved overall identification of HCC patients.

Conclusions: Plasma YB-1/p18 can identify patients with malignancies, independent of acute inflammation, renal impairment or liver dysfunction. The detection of YB-1/p18 in human plasma may have potential as a tumor marker for screening of high-risk populations, e.g. before organ transplantation, and should therefore be evaluated in larger prospective studies.

Keywords: cold shock proteins, liver transplantation, hepatocellular carcinoma, cancer screening, serum markers

\section{Background}

A pivotal role for cold shock proteins has been originally described in breast cancer, as these proteins relate to cell transformation and confer aggressive tumor growth $[1,2]$. The overexpression of one prototypic member of this

\footnotetext{
* Correspondence: peter.mertens@med.ovgu.de

+ Contributed equally

${ }^{2}$ Nephrology and Hypertension \& Endocrinology and Metabolic Disease, Otto-von-Guericke University Magdeburg, Leipziger Str. 40, 39120 Magdeburg, Germany Full list of author information is available at the end of the article
}

evolutionarily conserved protein family, denoted Y-box (YB) protein-1, in the mammarian gland results in breast carcinomas with $100 \%$ penetrance due to genetic instability, mitotic failure and centrosome amplification [2]. It is known that YB-1 expression levels significantly correlate with growth "aggressiveness" and consequently with prognosis [3]. Similar studies have been performed with prostate, epithelial ovarian [4], cisplatin-resistant ovarian [5] and non-small cell lung cancers [6] as well as synovial sarcomas and osteosarcomas [7]. The uniform finding is a
C Biomed Central 
correlation of upregulated, mostly nuclear YB-1 expression with poor outcome, e.g. early relapses and tumor growth, suggesting high YB-1 expression is an independent negative prognostic marker for many solid tumors. In particular, nuclear YB-1 overexpression was associated with more advanced diseases stages and poor prognosis in hepatocellular carcinoma [8].

Pleiotropic cellular functions have been attributed to YB-1, including regulation of gene transcription, mRNA processing, transport and stabilization as well as translation [9]. Transcription rates of proliferation-associated genes are upregulated by YB-1, e.g. DNA-polymerase- $\alpha$ [10], epidermal growth-factor receptor [11], plateletderived growth factor [12] and matrix metalloproteinase-2 [13]. YB-1 facilitates wt-p53 binding to DNA motifs, however not of mutated p53, and represses cell death-associated fas gene transcription [14]. The YB-1 potency in conferring tumor growth or cell survival is underscored by in vitro-studies showing that YB-1 activates the EGFR signaling pathway in human breast epithelial cells resulting in EGF-independent growth [15] and epithelial-mesenchymal transition [16]. Adenocarcinoma, hepatoma, fibrosarcoma, and colon cancer cells die with YB-1 knock-down $[17,18]$.

Recent findings from our laboratory indicate additional extracellular function(s) of YB-1. The protein is actively secreted by non-transformed and transformed cells following challenge with cytokines, e.g. PDGF-BB and TGF- $\beta$, and under oxidative stress $[19,20]$. The observation was unexpected as YB-1 lacks an N-terminal signal peptide motif. In this regard, YB-1 has similarities to other leaderless proteins, including interleukin-1 $\beta$, high mobility group box protein (HMGB1) and macrophage migratory inhibitory factor (MIF). Besides fulllength YB-1 protein, we observed secreted protein fragments in conditioned cell culture medium $[19,20]$.

The universal role of YB-1 in various solid tumors and its secretion by tumor cells prompted the current study in which we tested for the first time the potential clinical and diagnostic value of YB-1 or its fragments in human plasma in cohorts of healthy volunteers and patients with malignant as well as non-malignant diseases, using a novel immunoblotting system.

\section{Methods}

\section{Study populations}

In this survey, five independent cohorts were tested for the diagnostic value of $\mathrm{YB}-1 / \mathrm{p} 18$ in human plasma: (i) healthy volunteers $(\mathrm{n}=33)$, (ii) patients with chronic renal disorders and/or acute infections $(n=60)$, (iii) patients with solid tumors with hepatic metastases ( $\mathrm{n}=$ 20), (iv) patients with known and histologically proven non-metastasizing hepatocellular carcinoma ( $\mathrm{n}=25)$, and $(\mathrm{v})$ patients with chronic liver diseases $(\mathrm{n}=111)$ undergoing extensive evaluation before potential liver transplantation.

The control population comprised 33 healthy blood donors (19 male, 14 female, median age 39 , range 22-67 years) who had normal blood counts, normal aminotransferase activities and who tested negative for viral hepatitis markers and HIV. In order to determine renal function and acute or chronic inflammation as potential confounding variables for YB-1/p18, 60 patients from the Nephrology Department (37 male, 23 female, median 47 age, range 19-84 years) who presented to the Outpatient Clinic for a follow-up of chronic renal disorders $(\mathrm{n}=33,55 \%)$ or who presented due to acute infections ( $\mathrm{n}=27,45 \%)$ were included. All populations were age- and sex-matched with the liver disease study population.

The liver disease study population consisted of 111 patients (66 male, 45 female, with a median age of 46 years; range 18-70 years) with chronic liver diseases who were evaluated as inpatients for potential liver transplantation. Patient data, blood samples and anamnestic information were collected prospectively. The study was done according to the ethical guidelines of the Declaration of Helsinki, approved by the local ethics committee and after obtaining written informed consent. The evaluation for a potential liver transplantation is a highly standardized routine procedure including a broad variety of clinical, laboratory and other diagnostic measures [21]. Furthermore, the established tumor-markers $\alpha$-fetoprotein (AFP), carbohydrate antigen 19-9 (CA19-9), and carcinoembryonic antigen (CEA) were assessed in all patients.

With regard to the underlying etiology of the liver disease, patients were assigned to the following groups: (a) virus hepatitis $(n=32)$ with chronic hepatitis B $(n=14)$ or C $(n=18)$ virus infection; (b) biliary or autoimmune $(n=27)$ with primary $(n=4)$ or secondary $(n=2)$ biliary cirrhosis, primary sclerosing cholangitis $(n=17)$ or autoimmune hepatitis $(n=4)$; (c) alcohol-toxic or cryptogenic $(n=29)$ with alcohol-toxic $(n=20)$ and cryptogenic $(n=9)$ cirrhosis; and $(\mathrm{d})$ other origins $(n=23)$ with malignant liver tumors $(n=4)$, liver metastases $(n$ $=3$ ), liver cysts or benign tumors $(n=5)$ or hereditary metabolic or vascular disorders $(n=11)$. According to Child-Pugh's criteria [22], patients were found to have no cirrhosis $(n=18)$, Child A $(n=35), \mathrm{B}(n=44)$ or C $(n=14)$ cirrhosis.

Blood samples were collected in EDTA plasma separator tubes, centrifuged at $2000 \times \mathrm{g}$, and plasma was stored at $-80^{\circ} \mathrm{C}$. The scientist who performed the YB-1 blotting was blinded to the samples origin.

\section{Antibodies}

Monoclonal antibody generation for YB-1 has recently been described in detail [23]. Polyclonal antibodies were 
generated by immunization of rabbits with synthesized polypeptides corresponding to the indicated domains (details about peptide sequences are available on request) and affinity purified before usage for immunoblotting.

\section{YB-1 immunoblotting}

$0.1 \mu$ human plasma was separated on $12.5 \%$ SDS-PA gels, transferred to nitrocellulose, blocked with $2.5 \%$ milk in TBST and incubated overnight at $4^{\circ} \mathrm{C}$ with the primary monoclonal anti-YB-1 antibody (biotinylated Portugal; II 2C-5, 1:1000) [23]. Peroxidase-conjugated streptavidin (Dianova) and the ECL system (Amersham) were used for detection.

In each blot, one positive control sample obtained from a patient with metastasized small cell lung cancer was run in parallel, that was strongly $\mathrm{YB}-1 / \mathrm{p} 18$ positive. The YB-1/p18 signals were quantified by densiometry (NIH imager) and compared to the positive control signal which was assigned the optical density of "1.0". The relative optical density of the sample signals was calculated accordingly. All samples (patients and controls) were tested at least on two independent blots, with no mismatches (one positive, one negative) being detected.

\section{Recombinant YB-1 protein purification and MS/MS analysis}

A pRSET vector (Invitrogen) containing an insert coding for a hexahistidine T7 epitope-YB-1 fusion protein was a kind gift from Dr. Chien (University of California, San Diego). The recombinant YB-1 was synthesized with the pRSET prokaryotic coding sequence of rat YB-1 (also denoted EFIA). For expression in Escherichia coli, bacteria were induced with isopropyl- $\beta$ - $d$-thiogalactoside, followed by addition of M13/T7 helper phage encoding T7 polymerase. Expressed protein was released by sonication, and the purification of recombinant YB-1 was performed with $\mathrm{Ni}+$ affinity columns as outlined by the manufacturer (Invitrogen). Purity of the expressed YB-1 fusion product was ascertained by analytic SDS-polyacrylamide gel electrophoresis.

\section{In-gel digest}

The bands of interest were excised and in-gel digested in an adapted manner according to Shevchenko et al. [24].

\section{Mass spectrometric analysis}

Dried samples were dissolved in $10 \mu \mathrm{l} 2 \% \mathrm{ACN} / 0.1 \%$ trifluoroacetic acid (TFA) and applied to an Ultimate 3000 Nano-HPLC (Dionex, Germany), respectively. Each sample was first trapped on a $1 \mathrm{~mm}$ PepMap-trapping column (Dionex, Germany) for $10 \mathrm{~min}$ at $30 \mu \mathrm{l} / \mathrm{min} 2 \%$ ACN/0.1\% TFA and subsequently subjected to a $75 \mu \mathrm{m}$ ID, 5 cm PepMap C18-column (Dionex, Germany). Peptide separation was performed by an $\mathrm{ACN}$ - gradient at
$300 \mathrm{nl} / \mathrm{min}$. The separation column outlet was online coupled to a nano-spray interface (Bruker, Germany) of an Esquire HCT ETDII-Iontrap mass spectrometer (Bruker, Germany). Mass spectra were acquired in positive MS-mode, tuned for tryptic peptides. MS/MS-precursor selection was performed in an optimized automatic regime, with preference for double and triple charged ions. Every selected precursor was fragmented by collision induced dissociation (CID) and electron transfer dissociation (ETD), respectively. MS/MS spectra were processed by the Data Analysis and BioTools software from Bruker, Germany. Combined CID/ETD-derived fragment lists were analyzed by the MASCOT algorithm on in-house- and swissprot-databases.

\section{Statistics}

Results are reported as median and range, and differences between groups were assessed by Mann-Whitney U-test, Kruskal-Wallis-ANOVA or chi-square-test [25]. Correlation analyses were performed by Spearman rank correlation test. Receiver operating characteristic (ROC) curve analysis and the derived c-statistic were calculated to assess the accuracy of a marker for predicting an event [26]. All statistical analyses were performed using SPSS 12 (SPSS, Chicago, IL, USA).

\section{Results}

YB-1 protein complexes are present in plasma samples

To address whether YB-1 protein and fragments thereof are present in plasma samples of healthy volunteers, immunoblotting was performed. Diluted plasma samples were separated by electrophoresis, and protein blots were incubated with a biotinylated monoclonal anti-YB-1 antibody, that has been recently established in our laboratory [23]. Under non-reducing conditions, full-length YB-1 protein with an approximate size of $50 \mathrm{kDa}$ and a protein fragment of approximately $30 \mathrm{kDa}$ were detected, furthermore several high molecular weight complexes of more than $150 \mathrm{kDa}$ (Figure 1A, lane 1). Given the known propensity of YB-1 to multimerize [9], one explanation may be the formation of YB-1 homomultimers. Alternatively, YB-1 protein interactions with other hydrophilic proteins, e.g. albumin, may explain the existence of such macromolecular complexes. Following incubation of samples with $\beta$-mercaptoethanol and EDTA denoted reducing conditions $(\mathrm{R})$ the high molecular weight complexes were diminished, and bands corresponding to full-length YB-1 protein as well as the $30 \mathrm{kDa}$ proteolytic fragment were more pronounced (Figure 1A).

\section{Detection of an $18 \mathrm{kDa}$ YB-1 protein fragment in plasma samples of cancer patients}

The "YB-1" banding pattern obtained with the healthy control plasma sample was compared with one obtained 
A

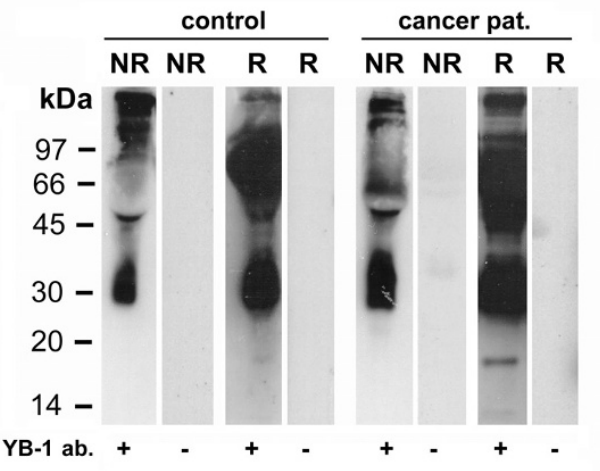

B

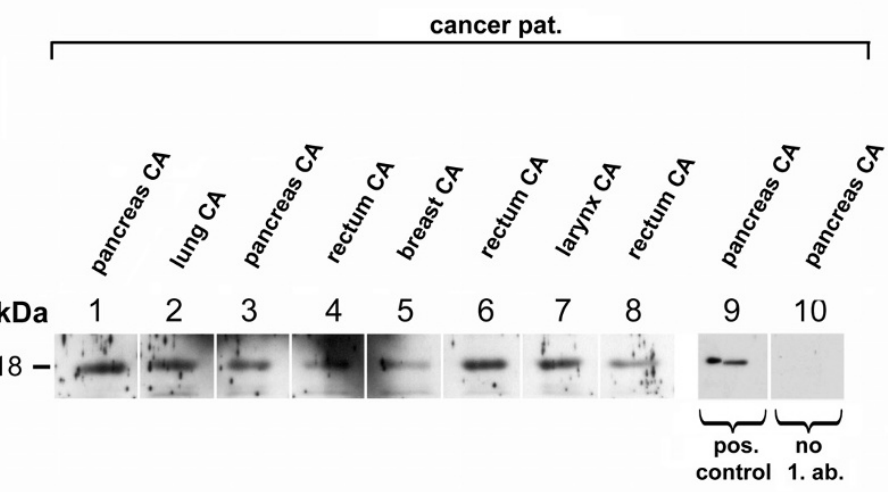

C

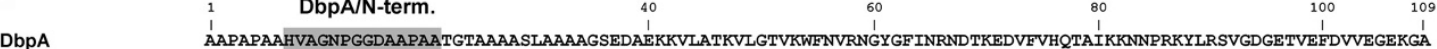

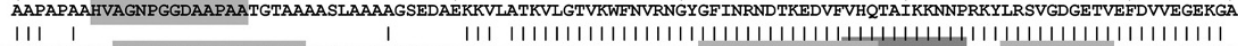

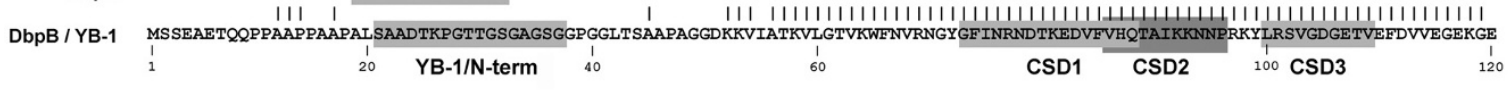

DbpA $\stackrel{110}{1}$ 130 170

190 $(10$ 'EAANVTGPDGVPVEGSRYAADRRRYRRGYYGRRRGPPRNYAGEEEEEGSGSSEGFDPPATDRQFSGARNQLRRPQYRPQYRQRRFPPYHVGQTFDRRSRVLPHPNRIQAGEIGEMKDGVPEG

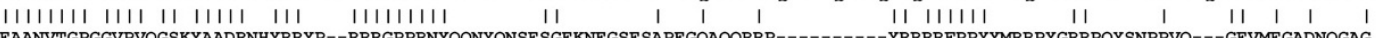

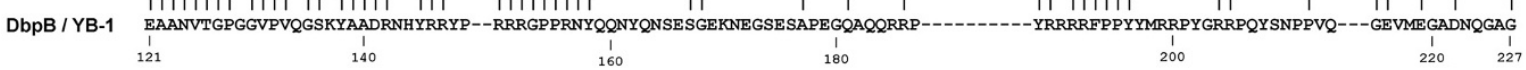

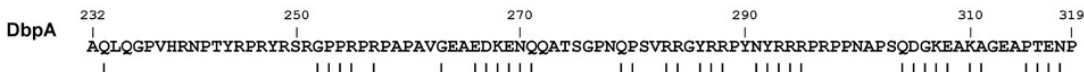

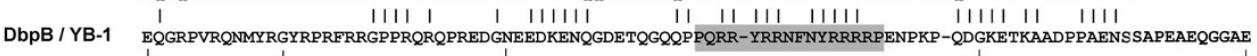

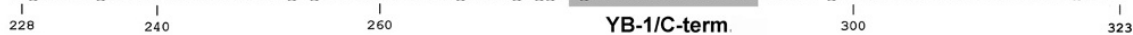

D

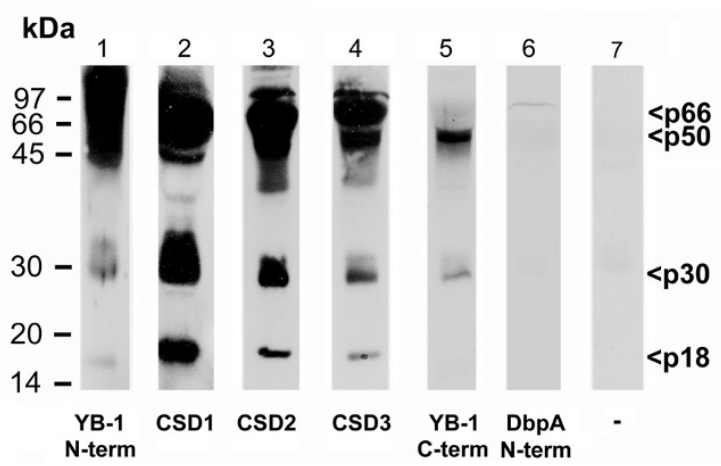

Figure 1 Establishment of a novel immunoblotting assay reveals a characteristic YB-1/p18 fragment in human plasma of cancer patients. A. Several complexes of molecular sizes >150, 50 and $30 \mathrm{kDa}$ are detected by a monoclonal biotinylated anti-YB-1 antibody in plasma from a healthy blood donor under non-reducing (NR) conditions (lane 1). Following addition of reducing compounds (R) the high molecular weight complex is markedly diminished, whereas bands at 66, 50 and $30 \mathrm{kDa}$ are more prominent (lane 3). A similar pattern is detected in plasma from a patient with lung cancer under non-reducing conditions (lane 5), but reducing conditions reveal an additional band corresponding to a relative molecular weight of $18 \mathrm{kDa}$ (lane 7). Specificity of the reaction was ensured by omission of the primary antibody (in lanes 2, 4, 6 and 8). B. In a series of plasma samples obtained from patients with various cancerous diseases, immunoblotting reveals the presence of a fast migrating band corresponding to $18 \mathrm{kDa}$ (lanes 1 through 8). Specificity of the reaction was confirmed by omission of the primary antibody (lane 10 vs. 9). C. Schematic overview of YB-1 (also denoted DNA-binding protein B, DbpB) amino acid composition compared with DbpA. Peptide-derived polyclonal antibodies were generated, as highlighted in the sequence, corresponding to the YB-1 N-terminus ( $\mathrm{N}$ term), C-terminus (C-term) and DbpA N-terminus (N-term). Three polyclonal antibodies were generated against epitopes residing in the cold shock domain (aa 52-128 of YB-1), denoted CSD1 through 3. D. Immunoblotting was performed with the same plasma sample as in Figure 1A, using polyclonal, peptide-derived antibodies as depicted in C. YB-1/p18 was visualized with polyclonal antibodies targeting epitopes of the cold shock domain (CSD) 1 through 3, however not the YB-1- or DbpA-specific antibodies. Also, a 30 kDa signal is detected by the CSD antibodies. Notably, no DbpA protein was present in the plasma sample. In lane 7, a negative control without primary antibody is shown. 
from plasma of a patient suffering from metastasizing lung cancer. This did not differ under non-reducing conditions; however, a faster migrating band of an approximate molecular mass of $18 \mathrm{kDa}$ appeared under reducing conditions (Figure 1A). Given this banding pattern difference we collected plasma samples from patients with various metastatic cancer diseases that originated in the breast, larynx, lung, pancreas and rectum. In all of these samples the $18 \mathrm{kDa}$ band was visualized by immunoblotting under reducing conditions (Figure $1 \mathrm{~B})$, which was denoted "YB-1/p18". Of note, the fulllength YB-1 protein was detectable in plasma samples of healthy controls and patients (Figure 1A), and no clear regulation of the abundantly present full-length YB-1 was noted.

Next, we generated a series of polyclonal, peptidederived affinity-purified antibodies in rabbits to map the domains within the YB-1 protein that correspond to YB-1/p18. A schematic overview of YB-1 (also denoted DNA-binding protein $\mathrm{B}, \mathrm{DbpB}$ ) and another member of this protein family, DbpA, is provided in Figure 1C. Six different antibodies were generated targeting either the $\mathrm{N}$ - (N-term) or C-terminal (C-term) part of YB-1 or the $\mathrm{N}$-terminus of DbpA as well as epitopes within the cold shock domain (CSD1-3) shared by both family members. By immunoblotting we were able to detect the p18 signal using polyclonal affinity purified antibodies generated with peptides CSD1-3, but no band was visualized with the YB-1 N-term, C-term or DbpA N-term antibodies (Figure 1D). By means of both $\mathrm{YB}-1$ specific $(\mathrm{N}$ term and C-term) antibodies, full-length YB-1 protein was detected in plasma samples ( $50 \mathrm{kDa}$; p50) [19], furthermore bands corresponding to molecular weights of 66 and $30 \mathrm{kDa}$ were detected. In contrast, the DbpAspecific antibody did not detect any protein in plasma samples, although reactivity of the antibody was assured by testing of nuclear protein extracts prepared with HepG2 hepatoma cells (data not shown). Therefore, the YB-1/p18 fragment includes the cold shock, but not the $\mathrm{N}$ - and C-terminal domains.

In order to investigate the identify of the $18-\mathrm{kD}$-fragment, we have performed ample immunoprecipitation experiments with the monoclonal as well as the polyclonal antibodies raised against YB-1 epitopes. None of these experiments were successful in elucidating the exact fragment composition (data not shown). Moreover, serum protein precipitation with ammonium sulphate and enrichment of YB-1/p18 by liquid chromatography also failed, most likely due to multimerization of the enriched protein fragment (not shown).

We thus used a different approach to further elucidate this unexpected banding pattern of YB-1. Recombinant affinity purified full-length YB-1 protein was subjected to similar gel electrophoresis and coomassie blue staining. Without further manipulation and under neutral $\mathrm{pH}(7.4)$, there were two dominant bands at about 50 and $25 \mathrm{kDa}$, alongside several other bands including one at $66 \mathrm{kDa}$ and the p18 band (Figure 2A). To ascertain that these bands of interest matching the signals from human plasma are all derivatives of the His-tagged recombinant protein, MS/MS analysis was performed on excised bands (Figure 2B). Interestingly, also the band running at $66 \mathrm{kDa}$ only contains $\mathrm{YB}-1$ protein, thereby likely reflecting dimers of different YB-1 fragments (Figure $2 \mathrm{~B}-1)$. The band at $18 \mathrm{kDa}$ was identified as truncated cold-shock domain with peptides corresponding to aa81-137 (Figure 2B-4). This is in full agreement with the findings obtained from plasma samples using the polyclonal and monoclonal YB-1 antibodies. Given the use of an expression plasmid with non-existing alternative splice sites and the expression in bacteria, it appears likely that YB-1/p18 is generated as an (auto-)proteolytic fragment.

\section{YB-1/p18 is a biomarker for cancers from different origin, independent of inflammation or renal failure}

The initial observation of the YB-1/p18 signal in cancer plasma samples raised the question whether this proteolytic YB-1 protein fragment is specifically present in cancer disease. Plasma samples from 33 healthy blood donors were assayed for the presence of $\mathrm{YB}-1 / \mathrm{p} 18$. None of the healthy blood donor plasma samples tested strongly positive for the $\mathrm{YB}-1 / \mathrm{p} 18$ fragment (Figure 3A). Furthermore, a series of 60 plasma samples was collected from outpatients with chronic renal disorders (n $=33$ ) and/or acute inflammatory diseases $(n=27$, e.g. urinary tract infection or pneumonia). YB-1/p18 and corresponding markers of inflammation (e.g. WBC count, procalcitonin, C-reactive protein) as well as renal function (e.g. glomerular filtration rate, serum creatinine) were determined. YB-1/p18 bands were prominent in 5 out of 60 patients (8\%), weakly present in 5 more patients $(8 \%)$ and absent in the remainder 50 patients (84\%). Importantly, there was no association of inflammatory marker levels or impairment of renal function with the presence of YB-1/p18 (U-test and Spearman rank correlation analysis, Figure $3 \mathrm{~B}$ ). Given these results, we assigned YB-1/p18 positivity in a sample, if the relative optical density (OD) exceeded 0.45 (as compared to the positive control carried in each blot with an arbitrary OD of 1.0).

To further elaborate on the detection of $\mathrm{YB}-1 / \mathrm{p} 18$ in various cancer diseases, plasma samples were analyzed from two cohorts of patients: metastatic disease of solid tumors, all demonstrating hepatic filiae, and patients with non-metastasizing hepatocellular carcinoma (HCC). YB-1/p18 was detected in 11 out of 25 (44\%) of all patients with HCC (Figure $3 \mathrm{C}$ ). Moreover, YB-1/p18 


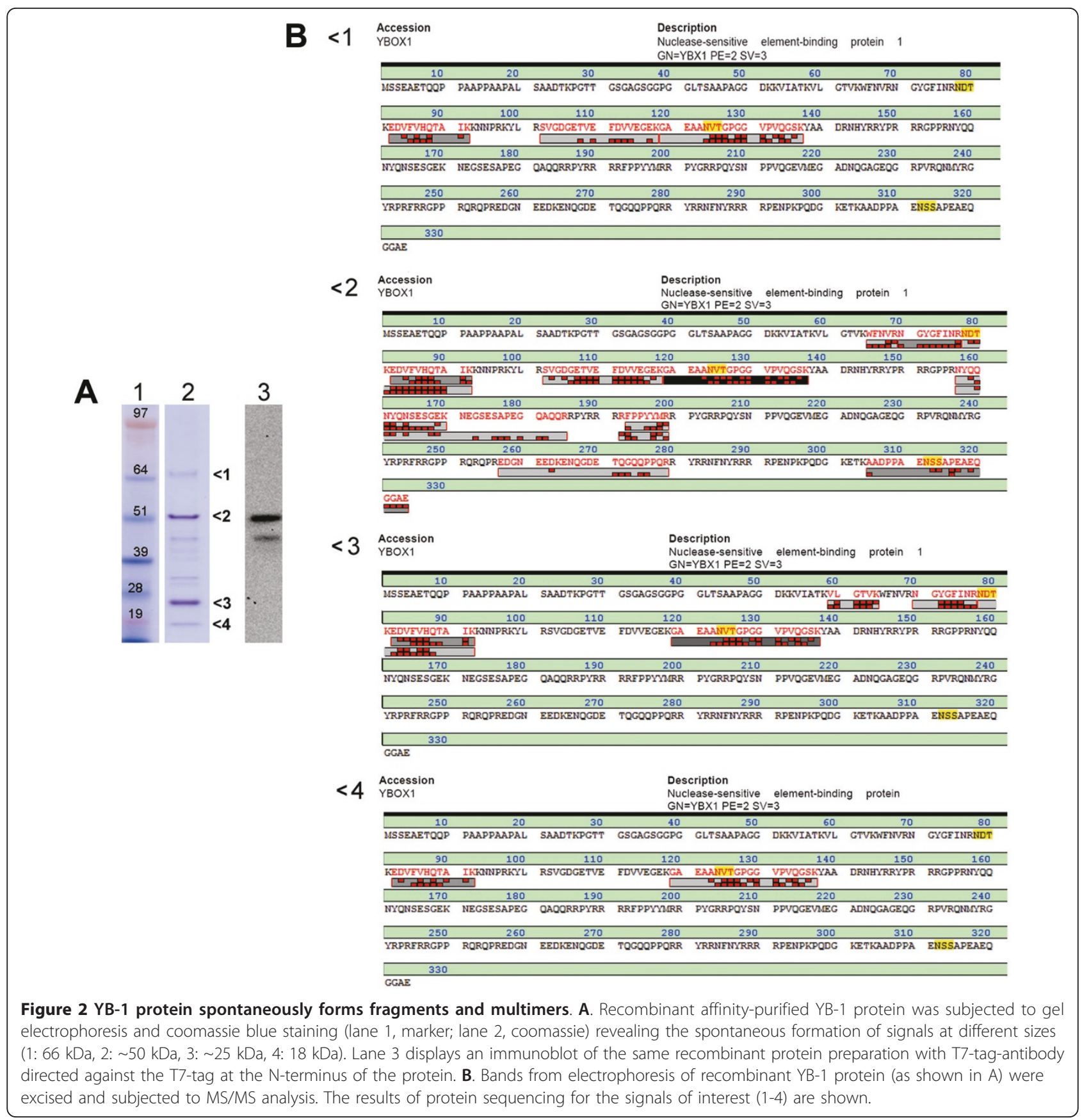

was present in 16 out of 20 plasma samples (80\%) collected from individual patients with different metastasizing cancers (Figure 3D).

\section{YB-1/p18 is not associated with the severity of liver cirrhosis in patients with chronic liver disease}

These data indicated that $\mathrm{YB}-1 / \mathrm{p} 18$ positivity may be a biomarker to identify cancer disease for screening purposes. We therefore included YB-1/p18 immunoblotting in a cohort of patients with chronic liver disease, a condition which predisposes to malignancies. These patients had not been diagnosed with cancer disease at study entry. All of them underwent most extensive clinical, radiologic/technical as well as laboratory examinations, because they were evaluated for potential liver transplantation (Table 1). Among all patients, 20/111 (18\%) showed positivity for YB-1/p18 by immunoblotting, as exemplified in Figure 4A. Positivity for YB-1/ p18 was not associated with advanced stages $B$ and $C$ of liver cirrhosis, as assessed by Child-Pugh's score (Table 


\section{A}

control pts.
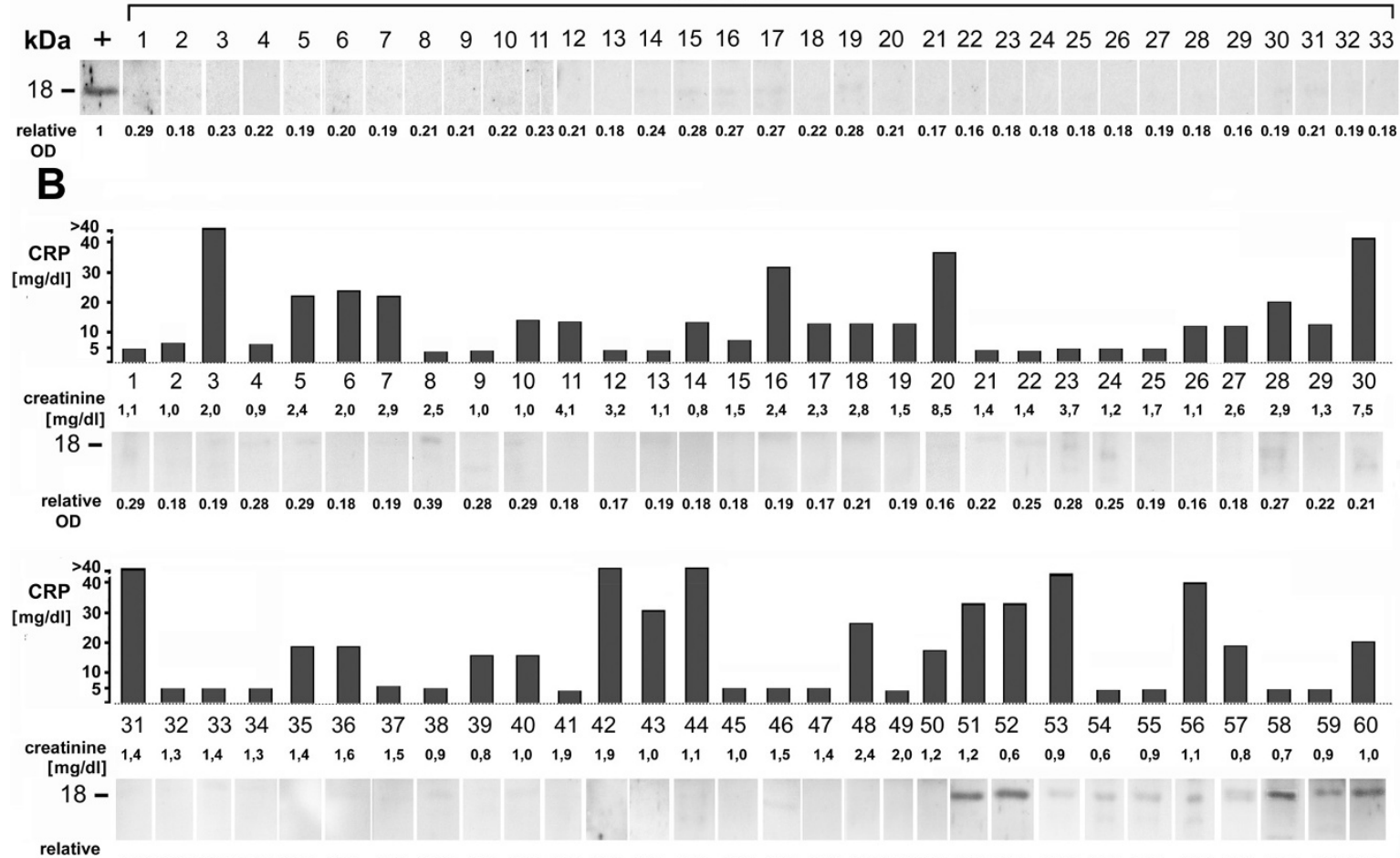

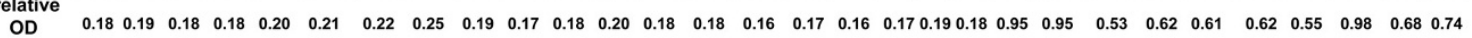

C

HCC

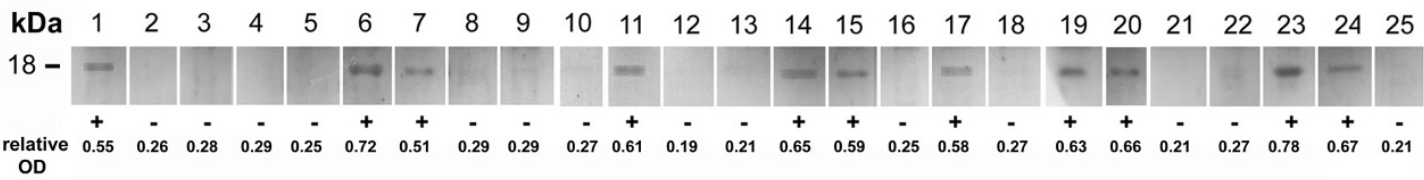

OD

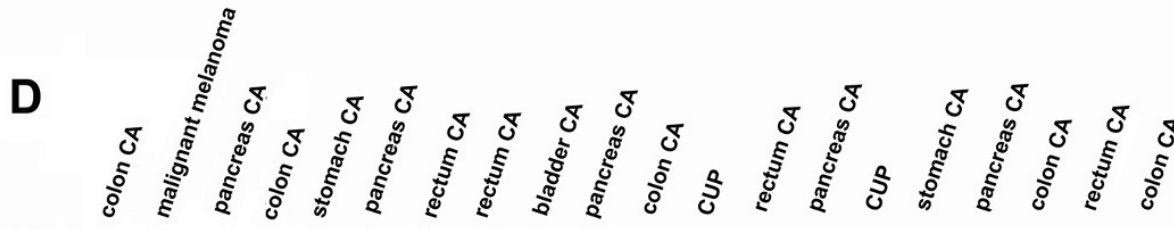

$\begin{array}{llllllllllllllllllllll}\text { kDa } & 1 & 2 & 3 & 4 & 5 & 6 & 7 & 8 & 9 & 10 & 11 & 12 & 13 & 14 & 15 & 16 & 17 & 18 & 19 & 20\end{array}$

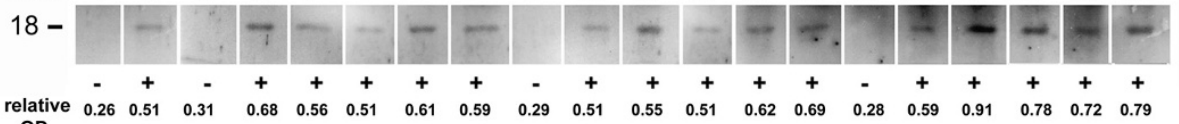

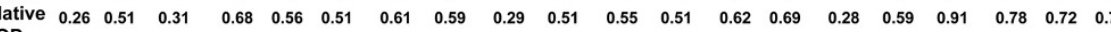

Figure 3 YB-1/p18 is largely absent in plasma samples of healthy blood donors, patients with inflammatory and renal diseases, but found in metastatic cancerous diseases and hepatocellular carcinoma. A. Plasma samples from 33 healthy blood donors were analyzed for the presence of YB-1/p18. In none of these samples YB-1/p18 was present (representative blots are shown). Positive control plasma from cancer patient is indicated by " + ". The relative optical density (OD) assessed by densiometry is given. Positivity was considered, if relative OD > 0.45. In each blot, one positive control sample obtained from a patient with metastasized small cell lung cancer was run in parallel, that was strongly YB-1/p18 positive. The YB-1/p18 signals were quantified by densiometry ( $\mathrm{NIH}$ imager) and compared to the positive control signal which was assigned the optical density of "1.0". The relative optical density of the sample signals was calculated accordingly. B. Analysis of 60 plasma samples collected from patients with various underlying, non-cancerous diseases was performed for the presence of YB-1/p18. Corresponding Creactive protein (CRP) and creatinine levels are provided for each patient. Representative blots are shown. $\mathbf{C}$. Immunoblotting with biotinylated monoclonal anti-YB-1 antibody was performed for YB-1/p18 in 25 individual patients with primary hepatocellular carcinoma (HCC).

Representative blots are shown. D. Immunoblotting with biotinylated monoclonal anti-YB-1 antibody was performed for YB-1/p18 in 20 individual patients with various advanced cancer diseases and liver metastases. Representative blots are shown. 
Table 1 Characteristics of the patients with chronic liver diseases

\begin{tabular}{|c|c|c|c|c|c|}
\hline & \multirow[t]{2}{*}{ All patients } & \multicolumn{4}{|c|}{ Stages of cirrhosis } \\
\hline & & no cirrh. & Child A & Child B & Child C \\
\hline [n] & 111 & 18 & 35 & 44 & 14 \\
\hline Sex (male/female) [n] & $66 / 45$ & $11 / 7$ & $18 / 17$ & $30 / 14$ & $7 / 7$ \\
\hline Age [years] median (range) & $46(18-70)$ & $46(18-65)$ & $41(18-64)$ & $48(20-70)$ & $40(26-69)$ \\
\hline \multicolumn{6}{|l|}{ Etiology of liver disease [n] } \\
\hline Virus hepatitis & $32(29 \%)$ & $1(6 \%)$ & $9(26 \%)$ & 17 (39\%) & $5(36 \%)$ \\
\hline Biliary or autoimmune & $27(24 \%)$ & $1(6 \%)$ & $14(40 \%)$ & $10(23 \%)$ & $2(14 \%)$ \\
\hline Alcohol or cryptogenic & $29(26 \%)$ & $1(6 \%)$ & $11(31 \%)$ & $10(23 \%)$ & $7(50 \%)$ \\
\hline Other origin & $23(21 \%)$ & 15 (83\%) & $1(3 \%)$ & $7(16 \%)$ & $0(0 \%)$ \\
\hline YB-1/p18 positivity [n] & $20(18 \%)$ & $6(33 \%)$ & $7(25 \%)$ & $5(11 \%)$ & $2(14 \%)$ \\
\hline
\end{tabular}

1). Furthermore, plasma YB-1/p18 detection did not correlate with markers of liver function (data not shown).

Subgroups of the study cohort showed differences in the detection of $\mathrm{YB}-1 / \mathrm{p} 18$. In patients with virus hepatitis, only $2 / 32(6 \%)$ tested YB-1/p18 positive. Patients with biliary liver diseases (22\%), alcoholic cirrhosis $(21 \%)$ or other liver diseases $(26 \%)$ showed YB-1/p18 positivity in significantly more patients $\left(\mathrm{p}=0.031, \mathrm{chi}^{2}\right.$ test).

\section{Sensitivity and specificity of YB-1/p18 and other tumor markers for hepatocellular carcinoma}

We hypothesized that these differences for plasma YB-1/ p18 in the subgroups may be due to a different prevalence of malignancies. Out of 111 patients, 15 (14\%) were diagnosed with HCC during evaluation, confirmed by histology. From these, $20 \%$ tested positive for YB-1/ p18 (Table 2A). In comparison, 6 (40\%) of all HCC patients tested positive for AFP (defined as AFP > 15 $\mu \mathrm{g} / \mathrm{L}), 5(33 \%)$ for CA19-9 (>37kU/L) and none for CEA $(>5 \mu \mathrm{g} / \mathrm{L})$. Of note, the combined assessment of HCC by CA19-9 and AFP determinations identified 8 out of 15 patients (53\%). Two of the remainder 7 patients with $\mathrm{HCC}$ were positive for $\mathrm{YB}-1 / \mathrm{p} 18$. Thus, the inclusion of $\mathrm{YB}-1 / \mathrm{p} 18$ to the routine tumor markers would have raised the number of identified cases to 10 out of 15 (67\%), although it does not have a high sensitivity to detect HCC by itself. Moreover, only one HCC patient tested positive for AFP and YB-1/p18, indicating that the combination of both markers is not likely to improve diagnostic accuracy. As mentioned above, 44\% of samples from a different (independent), retrospectively analyzed cohort of patients with established, histologically proven $\mathrm{HCC}$ were positive for $\mathrm{YB}-1 / \mathrm{p} 18$ (Figure 3C).

As the total population of patients was rather heterogeneous, we further investigated the subgroup of patients with chronic virus hepatitis to assess the specificity of the tumor markers. It is known that in conditions of chronic liver inflammation with regenerative processes AFP levels may be elevated $[27,28]$. Furthermore, cholestasis may result in increased plasma levels of CA19-9 [29,30]. In fact, up to $40 \%$ of cirrhotic patients may test positive for CEA [31] and up to $70 \%$ for CA19-9 [32], without any evidence of cancer. In our study population 23 patients exhibited chronic virus hepatitis but had no clinical, pathological or radiomorphological signs of $\mathrm{HCC}$ or other malignancies. Among these, only 1 (4\%) tested YB-1/p18 positive, whereas 4 (17\%) were positive for AFP, 13 (57\%) for CA19-9 and 5 (22\%) for CEA. Thus, AFP, CA19-9 and CEA have a higher rate of false-positive results compared to YB-1/ p18 in this cohort.

\section{YB-1/p18 is a sensitive marker to detect malignancies other than HCC}

Out of 111 patients included in our study, 5 were diagnosed with other malignancies, that were liver metastases of a neuroendocrine pancreatic tumor $(\mathrm{n}=3)$, cholangiocellular carcinoma $(\mathrm{n}=1)$ and B-cell type non-hodgkin lymphoma $(\mathrm{n}=1)$. Out of these patients, 3 (60\%) tested positive for $\mathrm{YB}-1 / \mathrm{p} 18$. In contrast, $1 / 5$ tested positive for AFP (20\%), 4/5 (80\%) for CA19-9, and none $(0 \%)$ for CEA. As mentioned above, one of the YB-1/p18 negative patients was diagnosed with nonhodgkin lymphoma. He had been treated by radiotherapy with curative intention prior to inclusion into the study and may be regarded as being in remission, thus expected to test negative for tumor markers (Table 2B).

Receiver operating characteristic (ROC) curve analyses were performed to assess the diagnostic value of YB-1 and the other tumor markers in identifying patients with either HCC or other malignancies (Figure 4). For patients with chronic liver diseases and HCC, AFP was found to be the best single predictive marker with a $\mathrm{c}$ statistic (AUC, area under the curve) of 0.668 . YB- $1 / \mathrm{p} 18$ $(\mathrm{c}=0.511)$, CA19-9 $(\mathrm{c}=0.404)$ and CEA $(\mathrm{c}=0.411)$ 

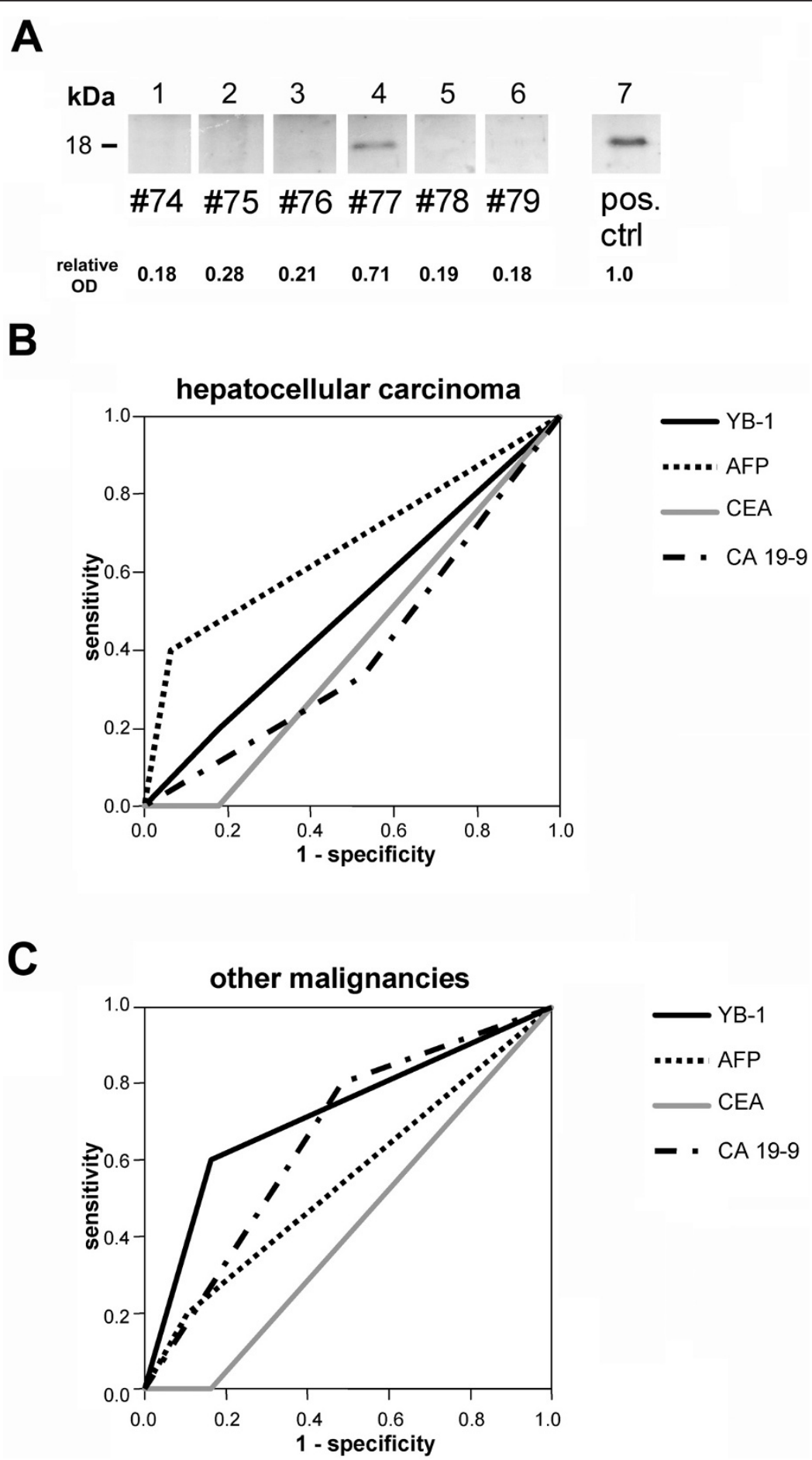

Figure 4 YB-1/p18 identifies malignancies other than HCC in patients with chronic liver disease. A. Representative Western Blot for YB-1 from patients' plasma showing a specific signal at $18 \mathrm{kDa}$. The patient's number is given; \#74 had hepatitis C virus related HCC, \#75 alcoholtoxic cirrhosis, \#76 alcohol-toxic cirrhosis and HCC, \#78 had hepatitis C virus infection and cirrhosis without HCC, \#79 had primary sclerosing cholangitis. Patient \#77 had a pancreatic neuroendocrine tumor with hepatic metastases. Plasma from a patient with small cell lung cancer served as a positive control (lane 7). The relative optical density (OD) assessed by densiometry is given. Positivity was considered, if relative OD > 0.45. B. Receiver operating characteristic (ROC) analysis shows that positivity for AFP (area under the curve, AUC: 0.668) was superior to YB-1/p18 (0.511), CA 19-9 (0.404) and CEA (0.411) in identifying patients with HCC among chronic liver disease patients. C. In contrast, positivity for YB-1/ p18 (AUC: 0.719) was the best predictor for other malignancies in the study population by ROC analysis, whereas AFP (0.548), CA 19-9 (0.657) or CEA (0.419) were less powerful. 
Table 2 Characteristics of the chronic liver disease patients with malignancies

\begin{tabular}{|c|c|c|c|c|c|c|c|c|}
\hline \multicolumn{9}{|c|}{ A. Patients with hepatocellular carcinoma (HCC) } \\
\hline Pat \# & diagnosis & $\begin{array}{c}\text { LDH } \\
(\mathrm{U} / \mathrm{l}) \\
{[80-240]}\end{array}$ & $\begin{array}{c}\text { CRP } \\
(\mathrm{mg} / \mathrm{l}) \\
{[<5]}\end{array}$ & $\begin{array}{c}\text { WBC } \\
(\mathrm{G} / \mathrm{l}) \\
{[4.3-10]}\end{array}$ & $\begin{array}{c}\text { AFP } \\
(\mu \mathrm{g} / \mathrm{l}) \\
{[<15]}\end{array}$ & $\begin{array}{c}\text { CEA } \\
(\mu \mathrm{g} / \mathrm{l}) \\
{[<5]}\end{array}$ & $\begin{array}{c}\text { CA19-9 } \\
(\mathrm{kU} / \mathrm{l}) \\
{[<37]}\end{array}$ & YB-1/p18 \\
\hline 9 & primary & 111 & 5 & 7.2 & $623++$ & 2 & 2 & pos. ++ \\
\hline 15 & $\mathrm{HCV}$ & $525++$ & $17++$ & 4.1 & 4 & 2 & $276++$ & neg. \\
\hline 16 & $\mathrm{HCV}$ & 230 & 5 & 6.2 & $1023++$ & 1 & 10 & neg. \\
\hline 17 & $\mathrm{HCV}$ & 162 & 5 & 2.8 & $87++$ & 2 & $59++$ & neg. \\
\hline 27 & primary & 179 & 5 & 6.6 & $12598++$ & 4 & $49++$ & neg. \\
\hline 38 & $\mathrm{HCV}$ & 211 & 5 & 5.1 & 9 & 3 & 36 & neg. \\
\hline 49 & $\mathrm{HCV}$ & $254++$ & 5 & 3.7 & 6 & 3 & $100++$ & neg. \\
\hline 51 & primary & 136 & 5 & 4.1 & 4 & 1 & 17 & neg. \\
\hline 59 & alcohol & 194 & $9++$ & 5.3 & 1 & 1 & 16 & pos. ++ \\
\hline 66 & alcohol & 182 & 5 & 3.8 & $155++$ & 3 & $50++$ & neg. \\
\hline 74 & $\mathrm{HCV}$ & 187 & 5 & 4.0 & 15 & 2 & 30 & neg. \\
\hline 76 & alcohol & 235 & $11++$ & 4.3 & $208++$ & 1 & 14 & neg. \\
\hline 86 & $\mathrm{HCV}$ & 184 & 5 & 3.4 & 6 & 1 & 34 & pos. ++ \\
\hline 88 & unknown & 175 & $7++$ & 7.2 & 4 & 2 & 16 & neg. \\
\hline 107 & $\mathrm{HCV}$ & $548++$ & 5 & 5.7 & 10 & 1 & 28 & neg. \\
\hline \multicolumn{9}{|c|}{ B. Patients with malignancies other than HCC } \\
\hline Pat \# & diagnosis & $\begin{array}{c}\text { LDH } \\
(\mathrm{U} / \mathrm{I}) \\
{[80-240]}\end{array}$ & $\begin{array}{c}\text { CRP } \\
(\mathrm{mg} / \mathrm{l}) \\
{[<5]}\end{array}$ & $\begin{array}{c}\text { WBC } \\
(\mathrm{G} / \mathrm{I}) \\
{[4.3-10]}\end{array}$ & $\begin{array}{c}\text { AFP } \\
(\mu \mathrm{g} / \mathrm{l}) \\
{[<15]}\end{array}$ & $\begin{array}{c}\text { CEA } \\
(\mu \mathrm{g} / \mathrm{l}) \\
{[<5]}\end{array}$ & $\begin{array}{c}\text { CA19-9 } \\
(\mathrm{kU} / \mathrm{l}) \\
{[<37]}\end{array}$ & YB-1/p18 \\
\hline 41 & PNET & $288++$ & $31++$ & 9.7 & 5 & 1 & $363++$ & neg. \\
\hline 50 & PNET & 121 & 5 & 7.2 & 5 & 1 & 8 & pos. ++ \\
\hline 53 & $\mathrm{CCC}$ & 206 & $7++$ & 5.8 & 9 & 4 & $177++$ & pos. ++ \\
\hline 77 & PNET & 97 & $6++$ & 4.4 & 3 & 1 & $84++$ & pos. ++ \\
\hline 90 & $\mathrm{NHL} *$ & 234 & 5 & 2.7 & $40++$ & 4 & $257++$ & neg. \\
\hline
\end{tabular}

HCV, Hepatitis C virus infection; PNET, pancreatic neuroendocrine tumor; CCC, cholangiocellular carcinoma; NHL, non-hodgkin lymphoma.

*Patient received prior curative radiotherapy.

were less powerful in the diagnosis of HCC (Figure 4B). In contrast, $\mathrm{YB}-1 / \mathrm{p} 18$ was the best single marker $(\mathrm{c}=$ $0.719)$ to identify patients with other malignancies among our study population (Figure $4 \mathrm{C}$ ) and proved superiority compared with AFP ( $\mathrm{c}=0.548)$, CA19-9 $(\mathrm{c}=$ 0.657 ) or CEA ( $c=0.419)$. However, it is important to note that other malignancies than HCC occurred rarely in our cohort, which limits the exact determination of sensitivity/specificity for detecting malignancies other than HCC for the tumor markers investigated.

\section{Analysis of 'non-tumorous' YB-1/p18 positive patients}

14 out of 111 patients had detectable YB-1/p18 plasma levels without apparent tumor disease at the time of investigation. However, in one patient, HCC was diagnosed in follow-up examinations within three months. $3 / 14$ patients were diagnosed with primary sclerosing cholangitis, that has a high risk for the development of cholangiocellular carcinoma, reaching 15\% [33]. Thus, it is likely that some of the $14 / 111 \mathrm{YB}-1 / \mathrm{p} 18$-positive patients without diagnosed tumor could indeed have had an underlying, 'subclinical' malignancy. However, a comprehensive analysis of the predictive value of YB-1/ p18 is hampered by (a) relatively small study cohort ( $\mathrm{n}$ = 111) with a rare incidence of new malignancies, and (b) short follow-up of the very high-risk patients due to the fact that these patients received liver transplantation on average within 6-12 months after evaluation [34].

\section{Discussion}

In this work, we identified circulating $18 \mathrm{kDa}$ fragments of YB-1 protein (YB-1/p18) in human plasma using immunoblotting with a monoclonal antibody. The presence of YB$1 /$ p18 in plasma samples may indicate malignant disorders of different origin. We found YB-1/p18 in about $80 \%$ of patients with advanced carcinomas and hepatic metastases, but in none of healthy volunteers. Potential confounding variables such as acute inflammations, renal or hepatic dysfunction could be excluded in non-cancerous cohorts. In a very well characterized group of 111 patients with chronic liver diseases, YB-1/p18 had a high sensitivity and reasonable specificity to identify patients with malignant tumors, suggesting its clinical potential as a tumor marker for screening 'high-risk' patient populations. 
Although many 'tumor markers' are widely used in monitoring cancer patients during therapeutic interventions, lack of sensitivity and specificity preclude the use of most existing markers for the early detection of malignancy [35]. The clinically best established general screening tumor marker at present is prostate-specific antigen (PSA), which is considered a specific indicator of prostate cancer, but still about 15\% of 'PSA-negative' men have biopsy-detected prostate cancer [36].

However, some markers can be useful in patient cohorts at high risk of developing certain carcinomas, e. g. AFP in patients with chronic virus hepatitis or liver cirrhosis at risk for HCC [28]. Several new markers have been suggested that could, alone or in combination with AFP, improve the accuracy of diagnosing HCC, such as AFP-L3, DCP/PIVKAII, CA242 or AAG [37-40]. In our study, AFP proved again to be superior in detecting HCC compared with CEA, CA19-9 and YB-1/p18 (Figure 4B). However, AFP or other 'established' markers were not powerful as screening tools for malignancies other than HCC. In fact, AFP and especially CEA or CA19-9 were elevated in a high number of patients with viral hepatitis without detectable malignancy, in line with previous reports $[31,32]$. YB-1/p18, on the other hand, was independent of the degree of liver cirrhosis and had a low rate of 'false-positive' results in liver disease patients as well as in patients with acute inflammatory or renal diseases, suggesting its usefulness in principle as a screening tool. YB-1/p18 furthermore tested negative in all blood donors ('healthy controls') and was not associated with inflammation or renal impairment ('non-malignant control patients'); all control populations were strictly age- and sex-matched to the liver patient cohort (Figure 3 ). In contrast to YB-1/ $\mathrm{p} 18$, renal function is a well appreciated confounding variable for most established tumor markers [41,42].

$\mathrm{YB}-1 / \mathrm{p} 18$ was more powerful in detecting malignancies other than HCC compared to AFP, CEA or CA19-9 in patients with chronic liver disease (Figure $4 C$ ), and patients with a variety of malignancies with liver metastases tested predominantly positive for YB-1/p18 (Figure $1 \mathrm{~B}, 3 \mathrm{C})$. The relatively high sensitivity of $\mathrm{YB}-1 / \mathrm{p} 18$ for various malignant disorders may be explained by its unique role in tumor biology. Nuclear YB-1 overexpression is a common finding in a variety of solid tumors, including breast, prostate, ovarian or lung cancer [4-7], and has been linked to tumor growth and survival of cancer patients in several studies. At present, it is unclear whether the detection of extracellular (circulating) YB-1/p18 fragment is associated with nuclear YB-1 overexpression in tumors. We therefore collected tumor tissue specimens $(n=20)$ and determined the subcellular YB-1 localization with monoclonal antibody by immunohistochemistry. At the same time we have determined the presence or absence of $\mathrm{YB}-1 / \mathrm{p} 18$ in corresponding serum samples. As a result, we were not able to find a positive correlation (unpublished observations). However, future studies will have to confirm these preliminary observations.

YB-1 appears to fulfill critical cellular functions such as transcriptional upregulation of proliferation-associated and downregulation of apoptosis-related genes or induction of drug-transporter genes (like MDR-1) involved in chemoresistance [1,7]. The exact function of extracellular YB-1 remains to be elucidated; however, by adding recombinant YB-1 protein to cell-lines in vitro we were able to demonstrate a profound promitogenic effect, suggesting that secreted YB-1 fragments could act as a tumor growth-promoting factor [19]. Besides the abundant presence of full-length YB-1 protein with a relative mobility corresponding to 50 $\mathrm{kDa}$ in SDS-PAGEs that was detected in all (healthy, non-malignant, malignant) plasma samples, the YB-1 fragment identified here, corresponding to a relative MW of $\sim 18 \mathrm{kDa}$ (denoted YB-1/p18) and harboring the evolutionarily conserved cold shock domain appears to be associated with the presence of malignant disease. Antibody and MS/MS mapping of different recombinant $\mathrm{YB}-1$ protein derivatives confirmed the cold-shock domain identity of the $18 \mathrm{kDa}$ fragment (Figure 2). However, it is currently unclear whether $\mathrm{YB}-1 / \mathrm{p} 18$ is released from the tumor cells or from infiltrating stromal cells. Our own experiments indicated that YB-1 processing may occur intracellularly within the vesicles that release YB-1 from the cells, but it is unknown whether this is a phenomenon of cancer and transformed cells only [19].

At present, the detection of YB-1/p18 can only be regarded as a "qualitative" tumor phenomenon, because we failed to quantitatively relate $\mathrm{YB}-1 / \mathrm{p} 18$ in plasma to either total full-length YB-1 in plasma or to nuclear YB1 expression in the tumor (not shown). The development of a specific ELISA system for YB-1/p18 may in the future allow to more quantitatively measure YB-1/ p18 levels. With such a more accurate quantification tool, new quantitative associations (e.g., between fulllength YB-1 in plasma or nuclear YB-1 expression levels) may be explored.

Given our promising results, we set out to prospectively evaluate the clinical use of YB-1/p18 in larger cohorts of patients with diagnosed malignant disease. In patients with various solid or hematological malignancies, YB-1/p18 is detected in more than $75 \%$ of cancer patients (FT, NK, PRM, unpublished observations). Tumor-specific factors (origin, staging, grading, tumor mass, response to treatment) are currently evaluated for their impact on YB-1/p18. The presented results suggest that $\mathrm{YB}-1 / \mathrm{p} 18$ should be further investigated as a 
potential screening biomarker for malignant diseases, preferably in high-risk patient populations.

\section{Conclusions}

The secreted $18 \mathrm{kD}$ fragment of the cold shock protein YB-1, YB-1/p18, can be reliably detected in human plasma of patients with advanced cancerous diseases, using a novel immunoblot assay. Our study suggests that plasma YB-1/p18 might bear diagnostic potential to identify patients with malignancies, independent of acute inflammation, renal impairment or liver dysfunction. The detection of YB-1/p18 in human plasma may have potential as a tumor marker for screening of highrisk populations, e.g. before organ transplantation, and should therefore be evaluated in larger prospective studies.

\section{List of abbreviations}

AAG: alpha-1-acid glycoprotein; AFP: alpha-fetoprotein; AFP-L3: lens culinaris agglutinin-reactive fraction; AUC: area under the curve; CA19-9: carbohydrate antigen; CEA: carcinoembryonic antigen; CSD: cold shock domain; DCP: desY-carboxy prothrombin; HCC: hepatocellular carcinoma; HMGB: high mobility group box protein; MIF: macrophage migratory inhibitory factor; PSA: prostate-specific antigen; ROC: receiver operating characteristic; TGF: transforming growth factor; WBC: white blood cell count; YB-1: Y-box protein-1; YB-1/p18: YB-1 protein fragment p18.

\section{Acknowledgements}

The study has been funded by the Sonderforschungsbereich (SFB) 854, project 1 (to PRM) and the German Research Foundation (DFG Ta 434/2-1, SFB-TRR57 to FT). We are grateful for expert assistance by A. Hübner and M. Möckel.

\section{Author details}

'Department of Medicine III, University Hospital Aachen, RWTH-Aachen, Pauwelsstrasse 30, 52074 Aachen, Germany. ${ }^{2}$ Nephrology and Hypertension \& Endocrinology and Metabolic Disease, Otto-von-Guericke University Magdeburg, Leipziger Str. 40, 39120 Magdeburg, Germany. ${ }^{3}$ Institute of Experimental Internal Medicine, Otto-von-Guericke University Magdeburg, Leipziger Str. 40, 39120 Magdeburg, Germany.

\section{Authors' contributions}

NK, AEN and CSE performed YB-1 immunoblots. TK and VS provided experimental tools and performed mass spectometric analyses. CT assisted in study design and patient recruitment. FT, NK and PRM designed the study, analyzed data and wrote the manuscript. All authors read and approved the final manuscript.

\section{Competing interests}

The authors declare that they have no competing interests.

Received: 12 October 2010 Accepted: 20 May 2011

Published: 20 May 2011

\section{References}

1. Bargou RC, Jurchott K, Wagener C, Bergmann S, Metzner S, Bommert K, Mapara MY, Winzer KJ, Dietel M, Dorken B, Royer HD: Nuclear localization and increased levels of transcription factor YB-1 in primary human breast cancers are associated with intrinsic MDR1 gene expression. Nat Med 1997, 3(4):447-450.

2. Bergmann S, Royer-Pokora B, Fietze E, Jurchott K, Hildebrandt B, Trost D, Leenders F, Claude JC, Theuring F, Bargou R, Dietel M, Royer HD: YB-1 provokes breast cancer through the induction of chromosomal instability that emerges from mitotic failure and centrosome amplification. Cancer Res 2005, 65(10):4078-4087.
3. Janz M, Harbeck N, Dettmar P, Berger U, Schmidt A, Jurchott K, Schmitt M, Royer HD: Y-box factor YB-1 predicts drug resistance and patient outcome in breast cancer independent of clinically relevant tumor biologic factors HER2, UPA and PAI-1. Int J Cancer 2002, 97(3):278-282.

4. Huang X, Ushijima K, Komai K, Takemoto Y, Motoshima S, Kamura T, Kohno K: Co-expression of $Y$ box-binding protein-1 and P-glycoprotein as a prognostic marker for survival in epithelial ovarian cancer. Gynecol Oncol 2004, 93(2):287-291.

5. Yahata H, Kobayashi H, Kamura T, Amada S, Hirakawa T, Kohno K, Kuwano M, Nakano $\mathrm{H}$ : Increased nuclear localization of transcription factor YB-1 in acquired cisplatin-resistant ovarian cancer. J Cancer Res Clin Oncol 2002, 128(11):621-626.

6. Shibahara K, Sugio K, Osaki T, Uchiumi T, Maehara Y, Kohno K, Yasumoto K, Sugimachi K, Kuwano M: Nuclear expression of the Y-box binding protein, YB-1, as a novel marker of disease progression in non-small cell lung cancer. Clin Cancer Res 2001, 7(10):3151-3155.

7. Oda Y, Ohishi Y, Saito T, Hinoshita E, Uchiumi T, Kinukawa N, Iwamoto Y, Kohno K, Kuwano M, Tsuneyoshi M: Nuclear expression of Y-box-binding protein-1 correlates with P-glycoprotein and topoisomerase II alpha expression, and with poor prognosis in synovial sarcoma. J Pathol 2003, 199(2):251-258.

8. Yasen M, Kajino K, Kano S, Tobita H, Yamamoto J, Uchiumi T, Kon S, Maeda M, Obulhasim G, Arii S, Hino O: The up-regulation of Y-box binding proteins (DNA binding protein A and Y-box binding protein-1) as prognostic markers of hepatocellular carcinoma. Clin Cancer Res 2005, 11(20):7354-7361.

9. Kohno K, Izumi H, Uchiumi T, Ashizuka M, Kuwano M: The pleiotropic functions of the Y-box-binding protein, YB-1. Bioessays 2003, 25(7):691-698.

10. En-Nia A, Yilmaz E, Klinge U, Lovett DH, Stefanidis I, Mertens PR: Transcription factor YB-1 mediates DNA polymerase alpha gene expression. J Biol Chem 2005, 280(9):7702-7711.

11. Wu J, Lee C, Yokom D, Jiang H, Cheang MC, Yorida E, Turbin D, Berquin IM, Mertens PR, Iftner T, Gilks CB, Dunn SE: Disruption of the Y-box binding protein-1 results in suppression of the epidermal growth factor receptor and HER-2. Cancer Res 2006, 66(9):4872-4879.

12. Stenina Ol, Shaneyfelt KM, DiCorleto PE: Thrombin induces the release of the Y-box protein $\mathrm{dbpB}$ from mRNA: a mechanism of transcriptional activation. Proc Natl Acad Sci USA 2001, 98(13):7277-7282.

13. Mertens PR, Steinmann K, Alfonso-Jaume MA, En-Nia A, Sun Y, Lovett DH: Combinatorial interactions of $\mathrm{p} 53$, activating protein-2, and $\mathrm{YB}-1$ with a single enhancer element regulate gelatinase $A$ expression in neoplastic cells. J Biol Chem 2002, 277(28):24875-24882.

14. Lasham A, Lindridge E, Rudert F, Onrust R, Watson J: Regulation of the human fas promoter by YB-1, Puralpha and AP-1 transcription factors. Gene 2000, 252(1-2):1-13

15. Berquin IM, Pang B, Dziubinski ML, Scott LM, Chen YQ, Nolan GP, Ethier SP: Y-box-binding protein 1 confers EGF independence to human mammary epithelial cells. Oncogene 2005, 24(19):3177-3186.

16. Evdokimova V, Tognon C, Ng T, Ruzanov P, Melnyk N, Fink D, Sorokin A, Ovchinnikov LP, Davicioni E, Triche TJ, Sorensen PH: Translational activation of snail 1 and other developmentally regulated transcription factors by YB-1 promotes an epithelial-mesenchymal transition. Cancer Cell 2009, 15(5):402-415.

17. Lasham A, Moloney S, Hale T, Homer C, Zhang YF, Murison JG, Braithwaite AW, Watson J: The Y-box-binding protein, YB1, is a potential negative regulator of the p53 tumor suppressor. J Biol Chem 2003, 278(37):35516-35523.

18. To K, Fotovati A, Reipas KM, Law JH, Hu K, Wang J, Astanehe A, Davies AH, Lee L, Stratford AL, Raouf A, Johnson P, Berquin IM, Royer HD, Eaves CJ, Dunn SE: Y-box binding protein-1 induces the expression of CD44 and CD49f leading to enhanced self-renewal, mammosphere growth, and drug resistance. Cancer Res 2010, 70(7):2840-2851.

19. Frye BC, Halfter S, Djudjaj S, Muehlenberg P, Weber S, Raffetseder U, EnNia A, Knott H, Baron JM, Dooley S, Bernhagen J, Mertens PR: Y-box protein-1 is actively secreted through a non-classical pathway and acts as an extracellular mitogen. EMBO Rep 2009, 10(7):783-789.

20. Raffetseder U, Rauen T, Djudjaj S, Kretzler M, En-Nia A, Tacke F, Zimmermann HW, Nelson PJ, Frye BC, Floege J, Stefanidis I, Weber C, Mertens PR: Differential regulation of chemokine CCL5 expression in monocytes/macrophages and renal cells by Y-box protein-1. Kidney Int 2009, 75(2):185-196. 
21. Tacke F, Wustefeld T, Horn R, Luedde T, Srinivas Rao A, Manns MP, Trautwein C, Brabant G: High adiponectin in chronic liver disease and cholestasis suggests biliary route of adiponectin excretion in vivo. $J$ Hepatol 2005, 42(5):666-673.

22. Yagmur E, Weiskirchen R, Gressner AM, Trautwein C, Tacke F: Insulin resistance in liver cirrhosis is not associated with circulating retinolbinding protein 4. Diabetes Care 2007, 30(5):1168-1172.

23. Dahl E, En-Nia A, Wiesmann F, Krings R, Djudjaj S, Breuer E, Fuchs T, Wild PJ, Hartmann A, Dunn SE, Mertens PR: Nuclear detection of Y-box protein-1 (YB-1) closely associates with progesterone receptor negativity and is a strong adverse survival factor in human breast cancer. BMC Cancer 2009, 9:410.

24. Shevchenko A, Wilm M, Vorm O, Mann M: Mass spectrometric sequencing of proteins silver-stained polyacrylamide gels. Analytical chemistry 1996, 68(5):850-858.

25. Tacke F, Brabant G, Kruck E, Horn R, Schoffski P, Hecker H, Manns MP, Trautwein C: Ghrelin in chronic liver disease. J Hepatol 2003, 38(4):447-454.

26. Yagmur E, Trautwein C, Gressner AM, Tacke F: Resistin serum levels are associated with insulin resistance, disease severity, clinical complications, and prognosis in patients with chronic liver diseases. Am J Gastroenterol 2006, 101(6):1244-1252.

27. Marrero JA, Lok AS: Newer markers for hepatocellular carcinoma. Gastroenterology 2004, 127(5 Suppl 1):S113-119.

28. Spangenberg HC, Thimme R, Blum HE: Serum markers of hepatocellular carcinoma. Semin Liver Dis 2006, 26(4):385-390.

29. Giannini E, Borro P, Botta F, Chiarbonello B, Fasoli A, Malfatti F, Romagnoli $P$, Testa E, Risso D, Lantieri PB, Antonucci A, Boccato M, Milone S, Testa R: Cholestasis is the main determinant of abnormal CA 19-9 levels in patients with liver cirrhosis. Int J Biol Markers 2000, 15(3):226-230.

30. Goonetilleke KS, Siriwardena AK: Systematic review of carbohydrate antigen (CA 19-9) as a biochemical marker in the diagnosis of pancreatic cancer. Eur J Surg Oncol 2006.

31. Collazos J, Genolla J, Ruibal A: Evaluation of the behavior of carcinoembryonic antigen in cirrhotic patients. Int J Biol Markers 1992, 7(4):244-248

32. Maestranzi $S$, Przemioslo $R$, Mitchell $H$, Sherwood RA: The effect of benign and malignant liver disease on the tumour markers CA19-9 and CEA. Ann Clin Biochem 1998, 35(Pt 1):99-103.

33. Tischendorf JJ, Hecker H, Kruger M, Manns MP, Meier PN: Characterization, outcome, and prognosis in 273 patients with primary sclerosing cholangitis: A single center study. Am J Gastroenterol 2007, 102(1):107-114.

34. Tacke F, Fiedler K, von Depka M, Luedde T, Hecker H, Manns MP, Ganser A, Trautwein C: Clinical and prognostic role of plasma coagulation factor XIII activity for bleeding disorders and 6-year survival in patients with chronic liver disease. Liver Int 2006, 26(2):173-181.

35. Duffy MJ: Role of tumor markers in patients with solid cancers: A critical review. Eur J Intern Med 2007, 18(3):175-184

36. Thompson IM, Pauler DK, Goodman PJ, Tangen CM, Lucia MS, Parnes HL, Minasian LM, Ford LG, Lippman SM, Crawford ED, Crowley JJ, Coltman CA $\mathrm{Jr}$ : Prevalence of prostate cancer among men with a prostate-specific antigen level $<$ or $=4.0 \mathrm{ng}$ per milliliter. N Engl J Med 2004, 350(22):2239-2246

37. Tao LY, Cai L, He XD, Liu W, Qu Q: Comparison of serum tumor markers for intrahepatic cholangiocarcinoma and hepatocellular carcinoma. Am Surg 2010, 76(11):1210-1213.

38. Beale G, Chattopadhyay D, Gray J, Stewart S, Hudson M, Day C, Trerotoli P, Giannelli G, Manas D, Reeves H: AFP, PIVKAll, GP3, SCCA-1 and follisatin as surveillance biomarkers for hepatocellular cancer in non-alcoholic and alcoholic fatty liver disease. BMC Cancer 2008, 8:200.

39. Bachtiar I, Santoso JM, Atmanegara B, Gani RA, Hasan I, Lesmana LA, Sulaiman A, Gu J, Tai S: Combination of alpha-1-acid glycoprotein and alpha-fetoprotein as an improved diagnostic tool for hepatocellular carcinoma. Clin Chim Acta 2009, 399(1-2):97-101.

40. Yamamoto K, Imamura H, Matsuyama Y, Kume Y, Ikeda H, Norman GL, Shums Z, Aoki T, Hasegawa K, Beck Y, Sugawara Y, Kokudo N: AFP, AFP-L3, DCP, and GP73 as markers for monitoring treatment response and recurrence and as surrogate markers of clinicopathological variables of HCC. J Gastroenterol 2010, 45(12):1272-1282
41. Nomura F, Koyama A, Ishijima M, Takano S, Narita M, Nakai T: Serum levels of five tumor markers for lung cancer in patients with chronic renal failure. Oncol Rep 1998, 5(2):389-392.

42. Filella X, Cases A, Molina R, Jo J, Bedini JL, Revert L, Ballesta AM: Tumor markers in patients with chronic renal failure. Int J Biol Markers 1990, 5(2):85-88.

\section{Pre-publication history}

The pre-publication history for this paper can be accessed here: http://www.biomedcentral.com/1471-2407/11/185/prepub

doi:10.1186/1471-2407-11-185

Cite this article as: Tacke et al:: Y-box protein-1/p18 fragment identifies malignancies in patients with chronic liver disease. BMC Cancer 2011 11:185.

\section{Submit your next manuscript to BioMed Central and take full advantage of:}

- Convenient online submission

- Thorough peer review

- No space constraints or color figure charges

- Immediate publication on acceptance

- Inclusion in PubMed, CAS, Scopus and Google Scholar

- Research which is freely available for redistribution 